\title{
Insulin receptor substrate-1 G972R single nucleotide polymorphism in Egyptian patients with chronic hepatitis $C$ virus infection and type 2 diabetes mellitus
}

\author{
Rania Nabil Bedair ${ }^{1}$, Gehan M. Magour ${ }^{1}$, Said Ahmed Ooda², Eman M. Amar ${ }^{1}$ and Ahmed M. Awad ${ }^{1 *}$
}

\begin{abstract}
Background: Insulin receptor substrate-1 (IRS1) plays a critical role in insulin signaling. IRS-1 gene polymorphism with glycine to arginine substitution (GGG ↔ AGG substitutions) in codon 972 (G972R) (rs1801278) is a common polymorphism of the IRS-1 gene, which may have a pathogenic role in the development of type 2 diabetes mellitus (type 2 DM) due to insulin resistance and impaired insulin secretion. In hepatitis $\mathrm{C}$ virus infection (HCV), the IRS proteins might be counterregulated by degradation, differential expression, or modification by phosphorylation in cells expressing HCV core protein, which inhibits the interactions of IRS-1 with both the insulin receptor and the downstream effectors of IRS-1. The present retrospective case-control study aimed to evaluate IRS-1 G972R (rs 1801278) SNP in Egyptian patients with HCV and type 2 DM, two hundred and two subjects including 100 males and 102 females The present work is a retrospective case-control study aimed to detect IRS-1 G972R (rs 1801278) SNP in Egyptian patients with chronic HCV infection and DM. The subjects were divided into the control group (group I) which included 50 apparently healthy volunteers of comparable age, gender, and socioeconomic status to patients; group II included 50 type 2 diabetic patients without chronic hepatitis C infection; group III included 52 chronic HCV-infected patients without type 2 diabetes mellitus; and group IV included 50 chronic hepatitis C-infected patients with type 2 diabetes mellitus. IRS-1 G972R (rs 1801278) genotyping was done by using polymerase chain reaction (PCR-RFLP) technique with restriction enzymes BstNI.
\end{abstract}

Results: HOMA-IR and QUICKI index was significantly higher in the patient groups (groups II, III, and IV) than controls $(P<0.001, P=0.019$, and $P<0.001$ respectively). There was a significant increase in minor allele (A) in groups II, III, and IV than controls $(P=0.007, P=0.017$, and $P=0.007$ respectively). There was increased frequency of mutant allele (A) than wild allele (G) of IRS-1 G972R polymorphism in type 2 diabetic patients with $\mathrm{BMl}<25 \mathrm{~kg} / \mathrm{m}^{2}$. The DM patients without HCV infection (group II), HCV patients without DM (group III), and HCV patients with DM (group IV) showed a significant decrease in GG genotypes and a significant increase in AA genotypes than the controls $(P=0.017, P=0.019$, and $P=0.009$ respectively). Body mass index and waist to hip ratio were significantly higher in DM patients without chronic hepatitis $C$ infection (group II) and in HCV patients with type 2 diabetes (group IV) than controls, in hepatitis C patients with type 2 diabetes (group IV) than controls, and in group IV than group III $(P<0.001)$.

(Continued on next page)

\footnotetext{
* Correspondence: dr_amawad@hotmail.com

${ }^{1}$ Chemical Pathology Department, Medical Research Institute, Alexandria

University, Alexandria, Egypt

Full list of author information is available at the end of the article
}

\section{Springer Open}

(c) The Author(s). 2021 Open Access This article is licensed under a Creative Commons Attribution 4.0 International License, which permits use, sharing, adaptation, distribution and reproduction in any medium or format, as long as you give appropriate credit to the original author(s) and the source, provide a link to the Creative Commons licence, and indicate if changes were made. The images or other third party material in this article are included in the article's Creative Commons licence, unless indicated otherwise in a credit line to the material. If material is not included in the article's Creative Commons licence and your intended use is not permitted by statutory regulation or exceeds the permitted use, you will need to obtain permission directly from the copyright holder. To view a copy of this licence, visit http://creativecommons.org/licenses/by/4.0/. 
(Continued from previous page)

Conclusion: IRS-1 G972R (rs 1801278) polymorphism might be a contributing risk factor for the development of type 2 DM. The mutant allele (A) of IRS-1 suggests the role of this SNP as risk factors for type 2 diabetes mellitus even in subjects with normal body weight. The increase of body mass index may be an independent risk factor for the development of type 2 diabetes mellitus.

Keywords: Hepatitis C virus, Type 2 diabetes mellitus, Insulin receptor substrate-1 gene polymorphism

\section{Background}

Approximately 399,000 people die each year from hepatitis $\mathrm{C}$, mostly from cirrhosis, hepatocellular carcinoma, and liver failure. HCV has been classified into six major genotypes; $\mathrm{HCV}$ genotype 4 is common in the Middle East and in Africa including Egypt $[1,2]$.

Type 2 diabetes mellitus (DM) is 1.8- to 2.5 -fold higher in patients with chronic $\mathrm{HCV}$ infection and two- to threefolds more prevalent in HCV than in HBV infection [3-5].

During $\mathrm{HCV}$ infection, the tumor necrosis factor- $\alpha$ system is activated and interleukin-6 levels are increased, which disturb tyrosine phosphorylation of insulin receptor substrate-1 (IRS-1) [6].

Insulin receptor phosphorylates tyrosine residues of an intracellular cytoplasmic adaptor protein, the IRS. The IRS-1 is the first member of the family to be identified. The IRS-1 binding and phosphorylation leads to an increase in the high-affinity glucose transporter-4 (GLUT4) molecules on the outer membrane of insulin-responsive tissues, including muscle cells and adipose tissue causing an increase in the uptake of glucose from the blood into these tissues. Defects in muscle IRS-1 expression and function lead to impairment in the insulin signaling pathway resulting in insulin resistance and DM [7-9].

The IRS-1 gene contains the entire 5 '-untranslated region and protein coding region in a single exon and is localized on chromosome 2. A glycine to arginine substitution (GGG $\leftrightarrow$ AGG substitutions) in codon 972 (G972R) (rs 1801278) is the common polymorphism of the IRS-1 gene, which may have a pathogenic role in the development of type $2 \mathrm{DM}$ due to insulin resistance and impaired insulin secretion [10-12]. IRS proteins might be counter-regulated by degradation, differential expression, or modification by phosphorylation in cells expressing HCV core protein which inhibits the interactions of IRS-1 with both the insulin receptor and the downstream effectors of IRS-1 [13].

Single nucleotide polymorphism in the IRS- 1 gene has been frequently studied as a candidate gene in DM. To the best of our knowledge, no much data are available on IRS-1 G972R SNPs in HCV-infected populations with DM.

\section{Methods}

The present work is a retrospective case-control study aimed to detect IRS-1 G972R (rs 1801278) SNP in Egyptian patients with chronic HCV infection and DM. We conducted the current study on two hundred and two subjects consisted of 100 males and 102 females, divided into the control group (group I) which included 50 apparently healthy volunteers of comparable age, gender, and socioeconomic status to patients; group II included 50 type 2 diabetic patients without chronic hepatitis $\mathrm{C}$ infection; group III included 52 chronic $\mathrm{HCV}$-infected patients without type 2 diabetes mellitus; and group IV included 50 chronic hepatitis C-infected patients with type 2 diabetes mellitus.

Any patient with hepatocellular carcinoma or any other malignancy, coexisting chronic viral infection like chronic hepatitis B (HBV), chronic kidney disease, liver cell failure, chronic pancreatitis, polycystic ovarian disease (PCOD), pregnant females, and those on treatment affecting insulin resistance were excluded from the study. All HCV-infected cases were active with positive PCR results during the time of the study.

The study was explained to all subjects, and written informed consents were taken from all of them. The study was conducted after approval of the Medical Research Institute, Alexandria University Ethical committee, no available reference number, and according to the Helsinki Declaration. The study was explained to all participating subjects, and written informed consents were taken from all of them.

Full history was taken from all subjects, full physical examination and anthropometric measurements including body mass index [14] and waist to hip ratio (WHR) [15] were done, and abdomen ultrasound was done to all subjects. Moreover, Child-Pugh classification [16] was done for the patient group only.

\begin{tabular}{llll}
\hline Child-Pugh scoring & & & \\
& 1 & 2 & 3 \\
Encephalopathy & None & Grades 1-2 & Grades 3-4 \\
Ascites & None & Mild/moderate & Severe \\
Serum albumin $(\mathrm{g} / \mathrm{dl})$ & $>3.5$ & $2.8-3.5$ & $<2.8$ \\
Serum total bilirubin $(\mathrm{mg} / \mathrm{dl})$ & $<2$ & $2-3$ & $>3$ \\
INR & $<1.7$ & $1.7-2.3$ & $>2.3$ \\
\hline
\end{tabular}

Child-Pugh classification

Risk group

Numerical score 
Methods (Continued)

$\begin{array}{ll}\text { 1- Child-Pugh class A } & \text { 5-6 points } \\ \text { 2- Child-Pugh class B } & 7-9 \text { points } \\ \text { 3- Child-Pugh class C } & 10-15 \text { points }\end{array}$

Also, there were some laboratory investigations performed on the participating subjects including fasting and postprandial serum glucose, glycated hemoglobin $\left(\mathrm{HbA}_{1} \mathrm{C}\right)$, lipid profile, renal function tests, and liver enzymes [17]. Serum insulin was included [18], for the determination of Homeostatic Model Assessment of Insulin Resistance (HOMA-IR) [19] and Quantitative Insulin Sensitivity Check (QUICKI) index [20].

HCV polymerase chain reaction (PCR) [21], for groups III and IV only; antibodies for HCV [21], for groups I and II only; and lastly surface antigen for hepatitis B [22] were assayed for all groups. We have performed some molecular studies as follows: extraction of genomic DNA was done from peripheral blood leukocytes by using ion-exchange column chromatography. IRS-1 G972R (rs 1801278) genotyping by using polymerase chain reaction (PCR-RFLP) technique with restriction enzymes BstNI was done [23].

The molecular studies which had been done in the current study included the following.

\section{DNA extraction from peripheral blood leucocytes [23]}

The genomic DNA extraction from peripheral blood leukocytes was carried out using column-based commercial genomic DNA extraction kits Thermo Scientific Gene JET $^{\mathrm{TM}}$ Whole Blood Genomic DNA Purification Mini Kit \#K0781 (Fermentas, Thermo, USA).

Then assessment of the integrity of the extracted genomic DNA was done by agarose gel electrophoresis (AGE). The Eppendorf containing the checked purified DNA in the elution buffer was tightly capped and stored till the time of PCR at $-20^{\circ} \mathrm{C}$.

\section{Polymerase chain reaction amplification using specific primers [23]}

A set of primers flanking the SNP region were used for the detection of insulin receptor substrate-1 G972R (rs 1801278) single nucleotide polymorphisms using the following reagent:

1. DreamTaq PCR Master Mix (2X) \# K1071(200 runs of $50 \mu \mathrm{l})$ Thermo Scientific ${ }^{\mathrm{TM}}$

2. DNA gel Loading Dye (6X) \# R0611: Thermo Scientific $^{\mathrm{TM}}$

3. Primers: A pair of primers G972R (rs 1801278) polymorphisms were used. The lyophilized primers were supplied by Invitrogen, UK, which were reconstituted by addition of sterile nuclease-free water as follows:

(a) Insulin receptor substrate-1 G972R (rs 1801278)

For the forward sense sequence, $165 \mu \mathrm{l}$ was added and $126 \mu \mathrm{l}$ for the reverse sense sequence to give a final concentration of $100 \mathrm{pmoles} / \mu \mathrm{l}$ for each and stored at $20{ }^{\circ} \mathrm{C}$. It was diluted to give a final concentration of 10 pmoles $/ \mu \mathrm{l}$.

I Primers for insulin receptor substrate-1 G972R (rs 1801278)

Forward sense sequence: (IRS-1- G02)

5'CTT CTG TCA GGT GTC CAT CC 3' (Tm (thermodynamic) $=62{ }^{\circ} \mathrm{C}$ )

Reverse antisense sequence: (IRS-1- G03)

5'-TGG CGA GGT GTC CAC GTA GC 3 (Tm (thermodynamic) $=66^{\circ} \mathrm{C}$ )

\section{Protocol of amplification}

In a 0.2-ml Eppendorf tube placed on ice, the following reagents were added and mixed:

\begin{tabular}{ll}
\hline DreamTaq PCR Master Mix (2X) & $12.5 \mu \mathrm{l}$ \\
Forward primer & $0.5 \mu \mathrm{l}(10 \mathrm{pmol})$ \\
Reverse primer & $0.5 \mu \mathrm{l}(10 \mathrm{pmol})$ \\
Extracted DNA & $1 \mu \mathrm{l}$ \\
Water nuclease free & $10.5 \mu \mathrm{l}$ \\
\hline
\end{tabular}

The total volume was $25 \mu \mathrm{l}$, and then the tubes were transferred to the thermal cycler (Quanta Biotech, UK) where the PCR conditions were adjusted (Table 1).

The amplified products were separated on $2 \%$ agarose gel electrophoresis after adding loading dye as follows: 2 $\mu \mathrm{l}$ loading dye added to $10 \mu \mathrm{l}$ of amplified DNA.

\section{Restriction digestion of PCR products using Mval (BstNI)} for insulin receptor substrate-1 G972R (rs 1801278) [23]

Restriction endonuclease enzymes, MvaI (BstNI) enzyme for insulin receptor substrate-1 G972R (rs 1801278) targeting specific sequence of the amplified DNA product for detection IRS-1 G972R (rs 1801278) gene polymorphisms.

\section{Reagents}

- MvaI (BstNI) $(10 \mathrm{U} / \mu \mathrm{l})$ restriction enzyme recognized $\mathrm{CC}^{\wedge} \mathrm{WGG}$ sites and cut best at $37^{\circ} \mathrm{C}$ in $\mathrm{R}$ buffer. It is used for insulin receptor substrate-1 G972R (rs 1801278) polymorphism. 
- $10 \mathrm{x}$ buffer $\mathrm{R}$ for Mval containing $10 \mathrm{mM}$ Tris-HCl (pH 7.4 at $25^{\circ} \mathrm{C}$ ), $400 \mathrm{mM} \mathrm{KCl}, 0.1 \mathrm{mM}$ EDTA, 1 $\mathrm{mM}$ DTT, $0.2 \mathrm{mg} / \mathrm{ml} \mathrm{BSA}$, and 50\% glycerol.

Reagents were supplied by ThermoFisher Scientific, stored at $-20^{\circ} \mathrm{C}$.

\section{Protocol for restriction enzymes}

In an Eppendorf tube, the following reagents were mixed:

\begin{tabular}{ll}
\hline Water (nuclease free) & $18 \mu \mathrm{l}$ \\
$10 \times \mathrm{R}$ buffer & $2 \mu$ \\
Amplified PCR product & $10 \mu$ \\
Restriction enzyme, BstNI & $2 \mu$ \\
\hline
\end{tabular}

Thus, the total volume was $32 \mu \mathrm{l}$. They were mixed gently, spin down for a few seconds, and incubated at 37 ${ }^{\circ} \mathrm{C}$ for $16 \mathrm{~h}$, and then the digested products were separated on agarose gel electrophoresis after adding loading dye as follows: $2 \mu \mathrm{l}$ of loading dye was added to $10 \mu \mathrm{l}$ of restricted DNA products.

\section{Agarose gel electrophoresis for the amplified and digested PCR products}

1) Gene Ruler ${ }^{\mathrm{TM}} 50$ bp DNA ladder (Thermo Fisher Scientific), the DNA fragments range from 50 to $1000 \mathrm{bp}$. It contains two reference bands: 250 and $500 \mathrm{bp}$.

2) Tris borate EDTA (TBE) buffer (10x) stock solution: working TBE (1x) buffer was prepared by measuring $100 \mathrm{ml}$ stock solution and completed to $1 \mathrm{l}$ of distilled water.

3) Agarose gel (wt/vol) 2.5\% then 100 volts was applied for about $45 \mathrm{~min}$ till the loading dye had migrated to near the end of the plate. The DNA will migrate towards the anode.

- A negative control, water (nuclease free), and a positive control, previous read samples, were allowed to run in case of amplified product detection.

Table 1 Thermal cycler condition of insulin receptor substrate-1 G972R (rs 1801278)

\begin{tabular}{llll}
\hline Phases & Cycle number & Temperature $\left({ }^{\circ} \mathrm{C}\right)$ & Time \\
\hline Initial denaturation & 1 & 95 & $1 \mathrm{~min}$ \\
Amplification & & & \\
• Denaturation & 35 & 95 & $1 \mathrm{~min}$ \\
- Annealing & & 61 & $45 \mathrm{~s}$ \\
• Extension & & 72 & $1 \mathrm{~min}$ \\
Final extension & 1 & 72 & $7 \mathrm{~min}$ \\
\hline
\end{tabular}

- Ultraviolet transillumination (302 nm) was used for visualization of the DNA bands.

\section{Results}

The amplified DNA leads to the formation of 263-bp amplicon. In the presence of the restriction enzyme MvaI (BstNI), allele G was digested to 159- and 81-bp fragments, whereas allele A yielded 108-bp, 81-bp, and 51-bp fragments, and the results were photographed.

So, in the amplified product G972R, the GG genotype appeared as two bands of 159 and $81 \mathrm{bp}$; the genotype GA appeared as four bands at 159, 108, 81, and $51 \mathrm{bp}$; and the AA genotype was expected to show three bands on 108, 81, and 51 bp (Figs. 1 and 2).

A missing 23-bp band did not appear. According to previous studies which used restriction enzyme MvaI (BstNI), GG genotype gives 159, 81, and 23 bp bands, and the AA genotype gives 108, 81, 51, and $23 \mathrm{bp}$. This band did not appear on our gel.

\section{Results}

There was no significant difference in both sex and age between the four studied groups $(P=0.101,0.183)$ respectively.

BMI was significantly higher in DM patients without chronic hepatitis C infection (group II) and in HCV patients with type 2 diabetes (group IV) than controls and in group IV than group III $(P<0.001)$. The highest BMI was observed in HCV-infected patients with T2DM (group IV).

WHR was significantly higher in group II and group IV than in controls, in group III and group IV than in group II, and in group IV than in group III $(P<0.001)$.

Serum levels of liver enzymes (AST, ALT, and GGT) were significantly higher in patients of groups III and IV than in controls and in patients of group II with $P<$ 0.001 for all. There was no significant difference between serum activities of AST and GGT in group II and in controls. By the reverse, serum activity of ALT was significantly increased in group II than in controls $(P=0.032)$. There was no significant difference between group IV and group III.

Serum cholesterol levels were significantly higher in patients of group II and significantly lower in patients of group III than in controls with $P<0.001$. Serum cholesterol level was significantly increased in patients of group II than in patients of group IV with $P<0.001$. There was no significant difference between group IV and controls $(P=0.835)$.

Serum triglyceride level was significantly higher in group II than in controls and group IV $(P<0.001$ for both), but there was no significant difference between HCV patients (groups III and IV) and controls. 


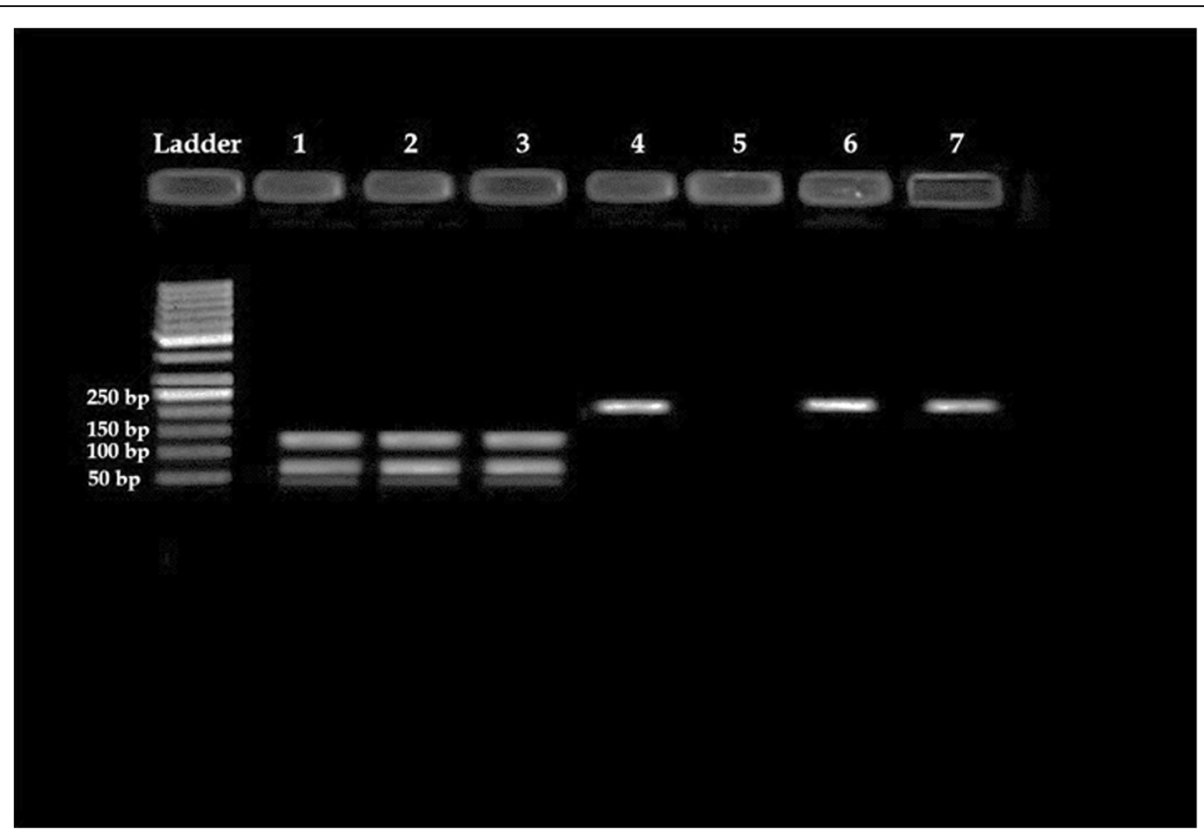

Fig. 1 Agarose gel electrophoresis (2.5\%) of BstNI-digested PCR product for IRS-1 G972R (rs 1801278). Ladder of 50-bp interval (50-1000 bp); lanes L1-3, AA; lanes 4, 6, and 7, amplified DNA before restriction; lane 5, negative control

High-density lipoprotein cholesterol (HDL-C) was significantly lower in patient groups (II, III, and IV) than in controls with $P<0.001$ for all. And it was significantly higher in patients of group II than in patients of groups III and IV with $P<0.001$.

Serum level of low-density lipoprotein cholesterol (LDL-C) was significantly higher in diabetes mellitus patient groups II and IV than in controls with $P<0.001$. And it was significantly higher in patients of group II than in patients of group IV with $P=0.012$. There was no significant difference between patients of group III and controls.

There was no significant difference between patients of group III and patients of group IV regarding $\mathrm{HCV}$ PCR level.

Fasting serum (FSG), postprandial serum glucose (PPSG), and glycosylated hemoglobin $\left(\mathrm{HbA}_{1} \mathrm{C} \%\right)$ were significantly higher in DM patients (groups II and IV) than in controls $(P<0.001$ for both) (Tables 2,3 , and 4).

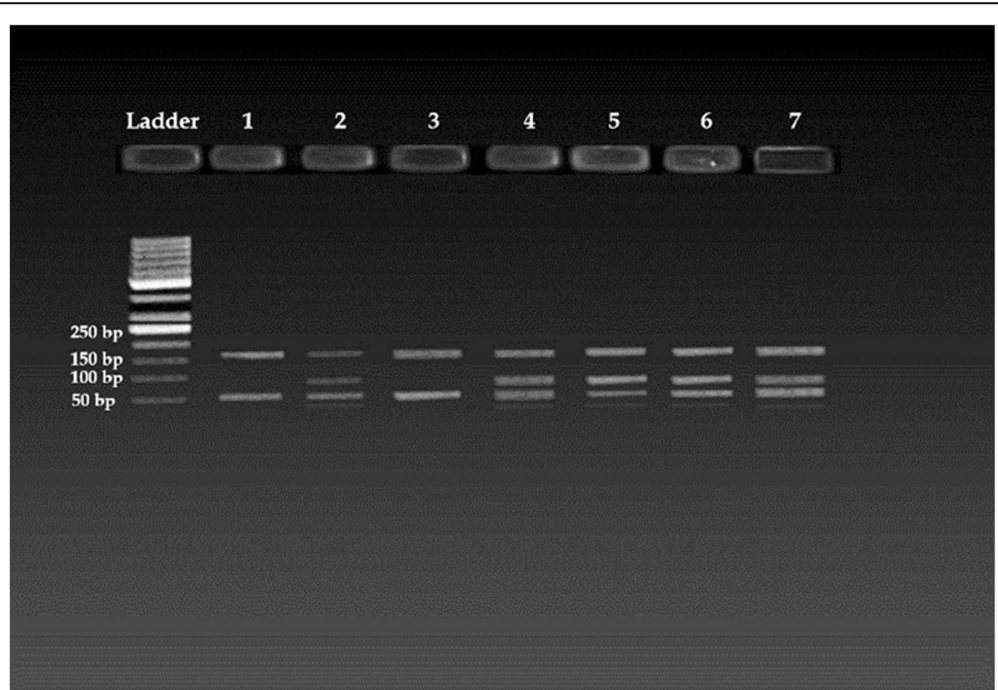

Fig. 2 Agarose gel electrophoresis (2.5\%) of BstNI-digested PCR product for IRS-1 G972R (rs 1801278). Ladder of 50-bp interval (50-1000 bp); lanes 1 and 3, GG; lanes 2 and $4-7$, GA 
Fasting insulin was significantly higher in the patient groups (groups II, III, and IV) than in controls $(P<$ $0.001)$. It was significantly lower in group III than in groups II and IV $(P=0.002$ and $P<0.001$ respectively). It was significantly higher in group IV than in group II $(P<0.001)$ (Tables 2,3 , and 4$)$.

HOMA-IR and QUICKI index was significantly different in the patient groups (groups II, III, and IV) than in controls $(P<0.001, P=0.019$, and $P<0.001$ respectively) (Table 2 ).

Urea and creatinine and uric acid were significantly different in the patient groups (groups II, III, and IV) than in controls (Table 3).

There was no statistically significant difference between groups III and IV regarding severity of liver cirrhosis assessed by Child-Pugh classification $(P=0.198)$.

It was noticed that the observed frequencies of the different genotypes of IRS-1 G972R polymorphism were compared to the expected frequencies, according to the Hardy-Weinberg equilibrium, in the diseased group which showed $P>0.05$ (after performing the chi-square test) indicating an agreement with the Hardy-Weinberg equilibrium.

The IRS-1 G972R polymorphism genotype distribution was significantly different between the four studied groups $(P=0.034)$. DM patients without $\mathrm{HCV}$ infection (group II), HCV patients without DM (group III), and HCV patients with DM (group IV) showed a significant decrease in GG genotypes and a significant increase in AA genotypes than the controls $(P=0.017, P=0.019$, and $P=0.009$ respectively). There was no significant difference in genotype distribution between HCV-infected patients without DM (group III) and $\mathrm{HCV}$-infected patients with DM (group IV) $(P=0.880)$. The highest frequency of wild genotype of IRS-1 polymorphism (GG) was in controls $(70 \%)$, while the lowest one was in group IV (42\%). The highest frequency of homozygous mutant genotype (AA) was in group II (8\%), whereas the mutant genotype was absent in controls. HCV patients with DM (group IV) had the highest frequency of heterozygous genotype (GA) (54\%) (Table 5, Fig. 3).

The allelic frequency was significantly different between the four studied groups $(P=0.031)$. There was a significant increase in minor allele (A) in groups II, III, and IV than in controls $(P=0.007, P=0.017$, and $P=$ 0.007 respectively) (Table 5, Fig. 4).

Testing the dominant mode of inheritance, there was a statistically higher frequency of exposed genotypes "GA\&AA" among the diabetics (group II) when compared to the control group (54\% vs $30 \%$ respectively; $P=0.016)$ with a substantial increase in insulin resistance and DM risk among the exposed group (GA and AA) with a crude odds ratio of odds ratio (2.739) (95\% confidence interval, 1.204-6.230) when compared to unexposed group (GG). After logistic regression analysis, the odds ratio was adjusted for BMI, age, and sex, to be 3.852 (95\% confidence interval, 1.248-11.887) $(P=0.019)$.

Testing the recessive model was not applicable as the odds ratio cannot be estimated because of the absence of (AA) genotype among the control subjects.

Also, testing the dominant mode of inheritance, there was a statistically higher frequency of exposed genotypes "GA\&AA" among HCV-infected patient group without diabetes (group III) than the control group (53.8\% vs $30 \%$ respectively; $P=0.016$ ) with a substantial increase in insulin resistance and DM risk among the exposed group (GA and AA) with a crude odds ratio of OR (2.722) (95\% confidence interval, 1.206-6.146) than the unexposed group (GG). After logistic regression analysis, the odds ratio was adjusted for BMI, age, and sex, to be insignificant 2.391 (95\% confidence interval, 0.9755.862) $(P=0.057)$.

Testing the recessive model was not applicable and the odds ratio cannot be estimated because of the absence of (AA) genotype among the control subjects.

Testing the dominant mode of inheritance, there was a statistically significant higher frequency of exposed genotypes "GA\&AA" among group IV when compared to the control group (58\% vs $30 \%$ respectively; $P=$ $0.005)$ with apparently increased in insulin resistance and DM risk among the exposed group (GA and AA) with a crude odds ratio of odds ratio 3.2222 (95\% confidence interval, 1.412-7.356) when compared to unexposed group (GG). After logistic regression analysis, the odds ratio was adjusted for BMI, age, and sex, to be insignificant 14.734 (95\% confidence interval, 0.576-376.811) $(P=0.104)$, meaning that genotype exposure by itself was insignificant but with other confounders like BMI and the risk of IR and DM increased.

Testing the recessive model was not applicable and odds ratio cannot be estimated because of the absence of (AA) genotype among the control subjects.

There was a significant positive correlation between serum level of ALT and HOMA-IR with $r=0.425$ and $P$ $=0.002$, and a significant negative correlation, inversely proportional, between serum level of ALT and QUICKI index in diabetic patients without chronic hepatitis $C$ infection with $r=-0.408$ and $P=0.003$.

There was a statistically significant difference regarding HOMA-IR and QUICKI index among different Child classes in groups III and IV, with HOMA-IR tending to increase and QUICK index tending to decrease with the increasing severity of liver cirrhosis, while there was no statistically significant difference regarding IRS-1 genotypes between different liver cirrhosis Child-Pugh classes in both groups (Tables 6 and 7). 
Table 2 Statistical significance of fasting serum glucose level (FSG) (mg/dl), postprandial serum glucose (PPSG) (mg/dl), HbA ${ }_{1} \mathrm{C}(\%)$, fasting insulin $(\mu \mathrm{U} U / \mathrm{ml})$, and HOMA-IR and QUICKI index in the studied groups

\begin{tabular}{|c|c|c|c|c|c|c|}
\hline & Group I $(n=50)$ & Group II $(n=50)$ & Group III $(n=52)$ & Group IV $(n=50)$ & Test of sig. & $P$ \\
\hline \multicolumn{7}{|l|}{ FSG (mg/dl) } \\
\hline Min.-Max. & $75.0-99.0$ & $129.0-322.0$ & $59.0-100.0$ & $83.0-766.0$ & \multirow[t]{5}{*}{$H=143.378$} & \multirow[t]{5}{*}{$<0.001^{*}$} \\
\hline Mean \pm SD. & $86.3 \pm 5.62$ & $195.2 \pm 51.82$ & $82.31 \pm 11.46$ & $182.68 \pm 106.6$ & & \\
\hline Median & 87.0 & 189.0 & 80.0 & 168.50 & & \\
\hline$P_{\text {Group I }}$ & & $<0.001^{*}$ & 0.239 & $<0.001^{*}$ & & \\
\hline Sig. bet. Grps & & \multicolumn{3}{|c|}{$P_{1}<0.001^{*}, P_{2}=0.132, P_{3}<0.001^{*}$} & & \\
\hline \multicolumn{7}{|l|}{ PPSG (mg/dl) } \\
\hline Min.-Max. & $85.0-130.0$ & 108.0-391.0 & $77.0-145.0$ & $85.0-540.0$ & \multirow[t]{5}{*}{$F=72.836$} & \multirow[t]{5}{*}{$<0.001^{*}$} \\
\hline Mean \pm SD & $102.3 \pm 12.9$ & $207.3 \pm 70.44$ & $101.6 \pm 17.87$ & $223.62 \pm 81.85$ & & \\
\hline Median & 99.0 & 201.0 & 95.0 & 210.0 & & \\
\hline$P_{\text {Group I }}$ & & $<0.001^{*}$ & 1.000 & $<0.001^{*}$ & & \\
\hline Sig. bet. Grps & & \multicolumn{3}{|c|}{$P_{1}<0.001^{*}, P_{2}=0.447, P_{3}<0.001^{*}$} & & \\
\hline \multicolumn{7}{|l|}{$\mathrm{HbA}_{1} \mathrm{C}(\%)$} \\
\hline Min.-Max. & $3.80-5.50$ & $6.20-13.70$ & $3.80-5.40$ & $5.40-12.20$ & \multirow[t]{5}{*}{$F=145.963$} & \multirow[t]{5}{*}{$<0.001^{*}$} \\
\hline Mean \pm SD. & $4.68 \pm 0.49$ & $8.75 \pm 2.01$ & $4.58 \pm 0.47$ & $7.89 \pm 1.42$ & & \\
\hline Median & 4.80 & 8.10 & 4.50 & 7.75 & & \\
\hline$P_{\text {Group I }}$ & & $<0.001^{*}$ & 0.974 & $<0.001^{*}$ & & \\
\hline Sig. bet. Grps & & $P_{1}<0.001^{*}, P_{2}=0$. & $P_{3}<0.001^{*}$ & & & \\
\hline \multicolumn{7}{|c|}{ Fasting insulin $(\mu \mathrm{lU} / \mathrm{ml})$} \\
\hline Min.-Max. & $1.20-10.10$ & $5.40-77.0$ & $2.40-25.30$ & $10.0-514.2$ & \multirow[t]{5}{*}{$H=121.986$} & \multirow[t]{5}{*}{$<0.001^{*}$} \\
\hline Mean \pm SD. & $5.75 \pm 2.65$ & $17.09 \pm 16.22$ & $9.19 \pm 3.65$ & $40.68 \pm 72.89$ & & \\
\hline Median & 5.65 & 11.0 & 9.30 & 18.65 & & \\
\hline$P_{\text {Group I }}$ & & $<0.001^{*}$ & $<0.001^{*}$ & $<0.001^{*}$ & & \\
\hline Sig. bet. Grps & & $P_{1}=0.002^{*}, P_{2}<0$. & $P_{3}<0.001^{*}$ & & & \\
\hline \multicolumn{7}{|l|}{ HOMA-IR } \\
\hline Min.-Max. & $0.30-2.20$ & $2.70-49.0$ & $0.50-5.30$ & $4.60-65.10$ & \multirow[t]{5}{*}{$H=157.864$} & \multirow[t]{5}{*}{$<0.001^{*}$} \\
\hline Mean \pm SD & $1.23 \pm 0.55$ & $9.14 \pm 11.09$ & $1.81 \pm 0.73$ & $12.76 \pm 11.04$ & & \\
\hline Median & 1.30 & 5.10 & 1.95 & 7.40 & & \\
\hline$P_{\text {Group I }}$ & & $<0.001^{*}$ & $0.019^{*}$ & $<0.001^{*}$ & & \\
\hline Sig. bet. Grps & & $P_{1}<0.001^{*}, P_{2}=0$. & $P_{3}<0.001^{*}$ & & & \\
\hline \multicolumn{7}{|l|}{ QUICKI index } \\
\hline Min.-Max. & $0.34-0.49$ & $0.23-0.33$ & $0.30-0.43$ & $0.21-0.31$ & \multirow[t]{5}{*}{$F=150.524$} & \multirow[t]{5}{*}{$<0.001^{*}$} \\
\hline Mean \pm SD. & $0.38 \pm 0.04$ & $0.30 \pm 0.03$ & $0.35 \pm 0.02$ & $0.28 \pm 0.02$ & & \\
\hline Median & 0.37 & 0.30 & 0.35 & 0.29 & & \\
\hline$P_{\text {Group I }}$ & & $<0.001^{*}$ & $<0.001^{*}$ & $<0.001^{*}$ & & \\
\hline Sig. bet. Grps & & $P_{1}<0.001^{*}, P_{2}=0$. & $P_{3}<0.001^{*}$ & & & \\
\hline
\end{tabular}

$P_{1} P$ value for comparing between group II and group III, $P_{2} P$ value for comparing between group II and group IV, $P_{3} P$ value for comparing between group III and group IV

\section{Discussion}

From the present study, it could be concluded that the minor allele "A" was associated with a statistically significant increased risk of developing insulin resistance and DM.

Although IRS-1 G972R polymorphism was studied in other Egyptian populations, the current study showed different genotype distributions. Shaker et al. [24] had studied the polymorphism on Egyptian patients, men and women, divided into three groups: DM lean, DM obese, and metabolic syndrome patients. The control group of healthy non-obese subjects. They found that most of the patient groups 
Table 3 Statistical significance of serum urea, creatinine, and uric acid in the studied groups

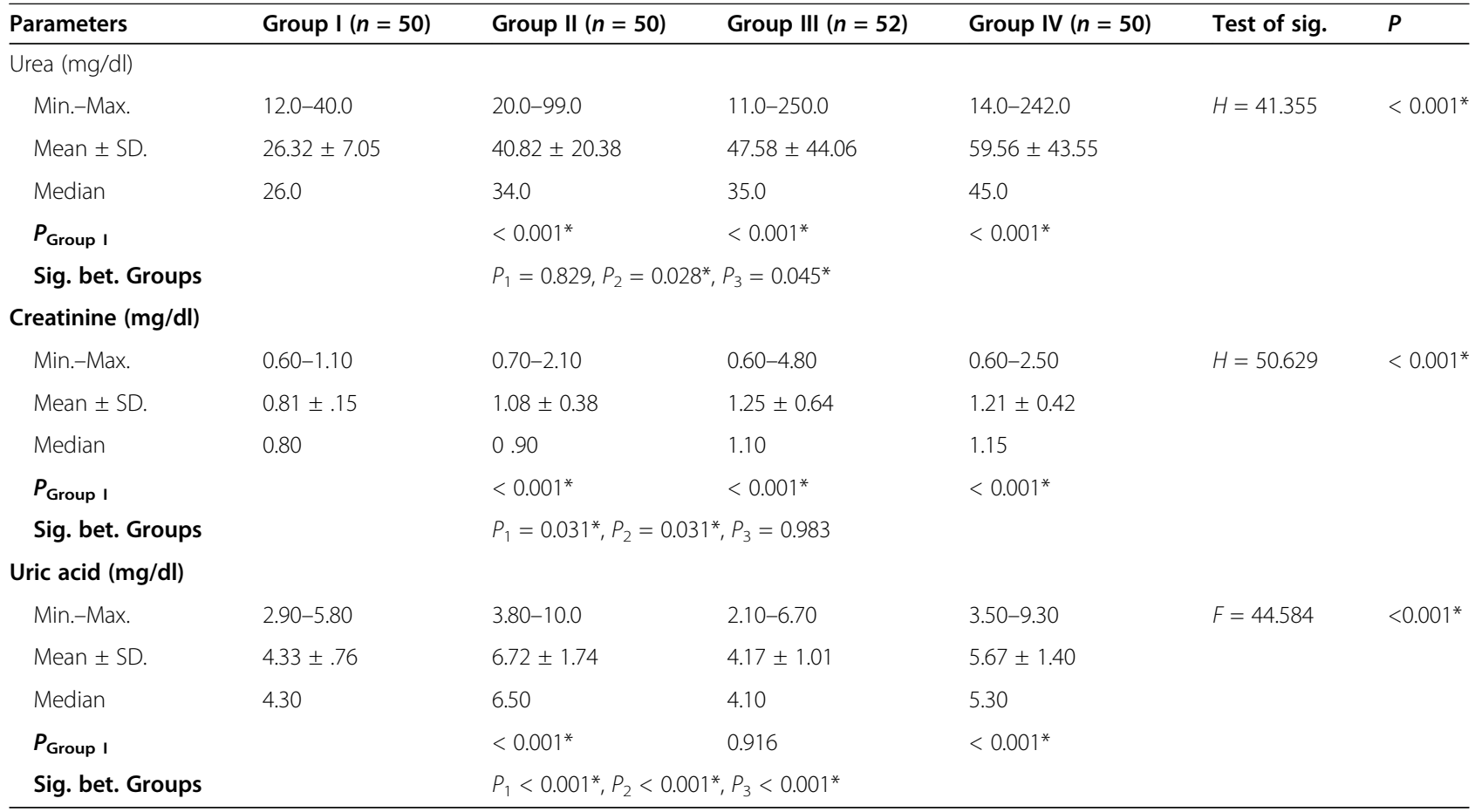

$F, F$ for ANOVA test, pairwise comparison bet. each 2 groups was done using post hoc test (Tukey); $H, H$ for Kruskal-Wallis test, pairwise comparison bet. each 2 groups was done using post hoc test (Dunn's for multiple comparisons test); $P, P$ value for comparing between the different groups; $P_{\text {Group } 1, P \text { value for }}$ comparing between group I and each other groups; $P_{1}, P$ value for comparing between group II and group III; $P_{2}, P$ value for comparing between group II and group IV; $P_{3}, P$ value for comparing between group III and group IV; Sig. bet. Groups, significance between groups

*Statistically significant at $P \leq 0.05$

were of GG genotype and the rest were of GA genotypes with no AA genotypes.

Elmougy et al. [23] studied IRS-1 G972R polymorphism on Egyptian subjects with PCOS in which patients and controls were divided into four categories based on their HOMA-IR results. They showed GA genotype only in HOMA-IR of $>6.4$, suggesting the association of IRS1 G972R polymorphism with higher insulin levels, as the study was conducted on females with PCOS categorized according to HOMA-IR illustrating the difference in genotype distribution between that study and the current study.

El-sisi et al. [25] also investigated the effect of IRS-1 G972R polymorphism on insulin secretion and how the polymorphism might predispose to sulfonylurea failure on 100 unrelated Egyptian patients with DM divided to two equal groups of those responsive to treatment and

Table 4 Liver cirrhosis Child-Pugh class in groups III and IV

\begin{tabular}{|c|c|c|c|c|}
\hline & Group III $(n=52)$ & Group IV $(n=50)$ & $x^{2}$ & $P$ \\
\hline \multicolumn{5}{|c|}{ Child-Pugh class } \\
\hline A & 6 & 12 & 3.236 & 0.198 \\
\hline B & 28 & 26 & & \\
\hline $\mathrm{C}$ & 18 & 12 & & \\
\hline
\end{tabular}

those resistant to sulfonylurea, $6 \%$ among controlled diabetic and $22 \%$ among uncontrolled were of GA genotype.

Recently, Yousef et al. [26] studied IRS-1 G972 R polymorphism on DM patients selected from the Department of Internal Medicine, Banha University. Patients who had a blood glucose level of $>250 \mathrm{mg} / \mathrm{dL}$ (severe hyperglycemia), aged over 30 years, and who used only insulin therapy during hospitalization were included. They found that genotype distribution was GG 70\%, GA $26 \%$, and AA $4 \%$. They concluded that IRS-1 genetic factor may be a significant genetic determinant for IR in DM patients during severe/acute-phase hyperglycemia.

The discrepancy between the genotype distribution of previously mentioned studies and the current study might be due to different sub-classifications of the diabetic patients; inclusion or exclusion of different confounders of insulin resistance such as BMI, WHR, dyslipidemia, PCOS, metabolic syndrome (MS), intake of antidiabetic drugs, and HCV infection; and different sample size. Also, the existence of mutant allele in the control group in all previous studies may suggest that phenotype features of glucose intolerance might not be developed due to epigenetic elements or subjective factors.

Furthermore, in obese adults, the prevalence of the IRS-1 972 GA genotype among insulin-resistant PCOS 
Table 5 Comparison between the four studied groups according to genotype distribution of IRS1 G972R (rs 1801278) polymorphism

\begin{tabular}{|c|c|c|c|c|c|c|c|c|c|c|}
\hline \multirow[t]{2}{*}{ Parameters } & \multicolumn{2}{|c|}{ Group I $(n=50)$} & \multicolumn{2}{|c|}{ Group II $(n=50)$} & \multicolumn{2}{|c|}{ Group III $(n=52)$} & \multicolumn{2}{|c|}{ Group IV $(n=50)$} & \multirow[t]{2}{*}{$x^{2}$} & \multirow[t]{2}{*}{$P$} \\
\hline & $N$ & $\%$ & $N$ & $\%$ & $N$ & $\%$ & $N$ & $\%$ & & \\
\hline \multicolumn{11}{|l|}{ IRS1 G972R } \\
\hline GG Homo wild & 35 & 70.0 & 23 & 46.0 & 24 & 46.2 & 21 & 42.0 & $12.243^{*}$ & ${ }^{M C} p=0.034^{*}$ \\
\hline GA Hetero & 15 & 30.0 & 23 & 46.0 & 26 & 50.0 & 27 & 54.0 & & \\
\hline AA Homo mutant & 0 & 0.0 & 4 & 8.0 & 2 & 3.8 & 2 & 4.0 & & \\
\hline Sig. bet. Grps & \multicolumn{10}{|c|}{${ }^{M C} P_{1}=0.017^{*},{ }^{M C} P_{2}=0.019^{*},{ }^{M C} P_{3}=0.009^{*},{ }^{M C} P_{4}=0.700,{ }^{M C} P_{5}=0.627,{ }^{M C} P_{6}=0.880$} \\
\hline G & 85 & 85.0 & 69 & 69.0 & 72 & 69.2 & 74 & 74.0 & $8.861^{*}$ & $0.031^{*}$ \\
\hline A & 15 & 15.0 & 31 & 31.0 & 32 & 30.8 & 26 & 26.0 & & \\
\hline Sig. bet. Grps & \multicolumn{10}{|c|}{$P_{1}=0.007^{*}, P_{2}=0.017^{*}, P_{3}=0.007, P_{4}=0.972, P_{5}=0.434, P_{6}=0.450$} \\
\hline
\end{tabular}

$X^{2}$ chi-square test, $M C$ Monte Carlo, $P P$ value for comparing between the different groups, common letters are not significant (i.e., different letters are significant), $P_{1} P$ value for comparing between group I and group II, $P_{2} P$ value for comparing between group I and group III, $P_{3} P$ value for comparing between group I and group IV, $P_{4} P$ value for comparing between group II and group III, $P_{5} P$ value for comparing between group II and group IV, $P_{6} P$ value for comparing between group III and group IV, Sig. bet. Grps significance between groups

*Statistically significant at $P \leq 0.05$

patients in other studies ranged from 4.9 to $8 \%$ such as Sir-Petermann et al. [27], Sir-Petermann et al. [28], Villuendas et al. [29], and Dravecká et al. [30] found no heterozygous mutation. This was lower than in the current study. Still, the increased frequency of GA and AA in the present work might be due to the difference in racial and ethnic distribution and the lack of data concerning the prevalence of the polymorphism in DM specifically.

Assuming a dominant model of inheritance of IRS-1 G972R (rs1801278), the exposed group was considered as subjects with both (AA and GA) genotypes combined, while the unexposed group was considered as subjects with only (GG) genotype. Results of the present study revealed a statistically higher frequency of exposed genotypes (AA and GA) among DM patients without HCV (group II) than the control group, with a substantial increase in insulin resistance and DM risk among the exposed group (GA and AA).

This association between IRS-1 G972R (rs1801278), insulin resistance, and DM risk among DM patients without $\mathrm{HCV}$ infection (group II) remained after performing logistic regression analysis to adjust for some important insulin resistance confounding factors (BMI, age, and sex).

On the contrary, $\mathrm{HCV}$-infected patients with $\mathrm{DM}$ (group IV) showed a statistically significant higher frequency of exposed genotypes (AA and GA) among group IV than the control group, with an apparent increase in insulin resistance and DM risk among the

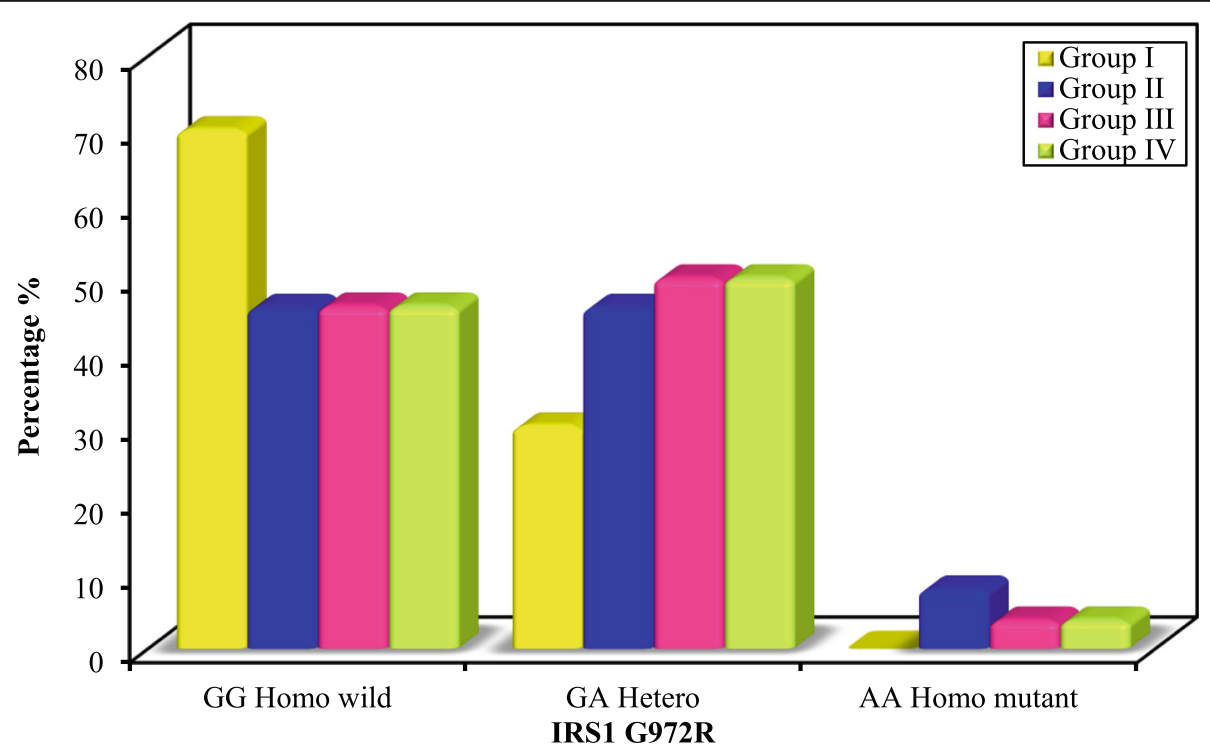

Fig. 3 Comparison between the four studied groups according to IRS1 G972R genotype distribution 


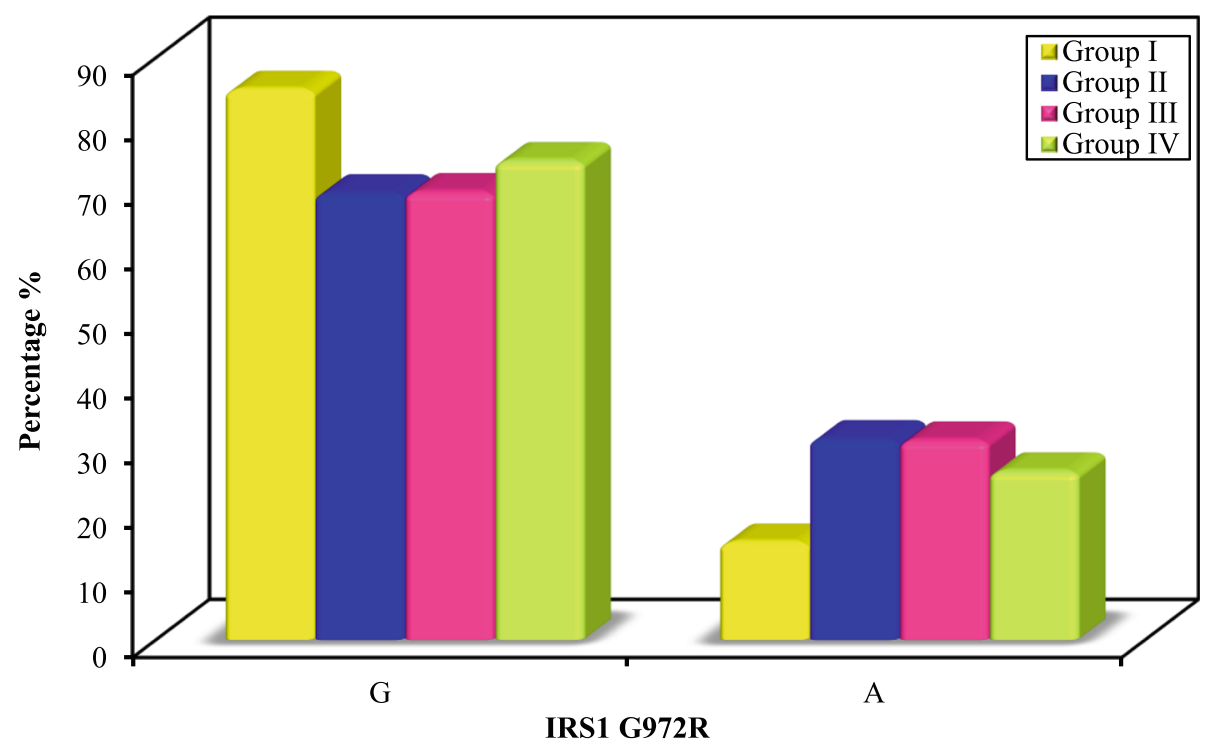

Fig. 4 Comparison between the four studied groups according to IRS1 G972R allele frequency

exposed group. After logistic regression analysis, the odds ratio was adjusted for BMI, age, and sex, to be insignificant, suggesting that genotype exposure by itself was insignificant but with other confounders like BMI, the risk of IR, and DM increased.

In agreement with the current study, IRS-1G972R polymorphism was shown to be associated with insulin resistance in many studies with different several populations and meta-analyses about DM. McGettrick et al. [31] determined the molecular mechanism by which this polymorphism was linked to insulin resistance. Burguete-Garcia et al. [32] in the Mexican population suggested the role of IRS-1G972R SNP in the genetic susceptibility to DM. Moreover, Huri et al. [33] in Malaysia using the polymerase chain reaction-restriction fragment length polymorphism method where a polymorphism in IRS-1 G972A showed a significant predictor of both insulin resistance and worsening of glycemic control.

However, the association between the IRS-1 G972R variant with DM has been controversial throughout the literature, and contrary to the current study, the lack of association has been also reported in other studies. Zeggini et al. [34] and Arikoglu et al. [12], in Turkish population; Bodhini et al. [35], in a South Indian; Elmougy et al. [23], in Egyptians; and Alsalman et al. [36], in Saudi Arabia population argued the lack of association between IRS-1 G972R and IR in their study due to multiple different genes and variants thought to be effective in the development of insulin resistance and DM.

These discrepancies in results might be due to insufficient statistical power and lack of adjustment for

Table 6 Insulin resistance (assessed by HOMA-IR and QUICKI index) and genotypes of IRS-1 SNP in relation to the degree of liver cirrhosis (assessed by Child-Pugh classification) in group III

\begin{tabular}{llllr}
\hline & Child class A & Child class B & Child class C & Test of sig. \\
\hline HOMA-IR & & & & \\
Min.-Max. & $0.80-5.30$ & $0.50-2.40$ & $0.90-2.40$ & $F=3.324$ \\
Mean \pm SD. & $2.267 \pm 1.650$ & $1.589 \pm 0.501$ & $1.994 \pm 0.448$ & 0.044 \\
QUICKI index & & & & \\
Min.-Max. & $0.30-0.40$ & $0.33-0.43$ & $0.33-0.39$ & 0.040 \\
Mean \pm SD. & $0.352 \pm 0.040$ & $0.361 \pm 0.022$ & $0.342 \pm 0.018$ & \\
Genotype & & & & $X^{2}=8.934$ \\
GG & 1 & 18 & 5 & 0.063 \\
GA & 5 & 9 & 12 & \\
AA & 0 & 1 & 1 & \\
\hline
\end{tabular}


Table 7 Insulin resistance (assessed by HOMA-IR and QUICKI index) and genotypes of IRS-1 SNP in relation to the degree of liver cirrhosis (assessed by Child-Pugh classification) in group IV

\begin{tabular}{llllr}
\hline & Child class A & Child class B & Child class C & Test of sig. \\
\hline $\begin{array}{l}\text { HOMA-IR } \\
\text { Min.-Max. }\end{array}$ & $4.60-29.60$ & $5.10-27.50$ & $5.00-65.10$ & $F=8.689$ \\
Mean \pm SD. & $8.867 \pm 8.384$ & $9.904 \pm 5.418$ & $22.833 \pm 16.102$ & 0.001 \\
QUICKI index & & & & $F=6.668$ \\
Min.-Max. & $0.25-0.31$ & $0.21-0.30$ & $0.23-0.30$ & 0.003 \\
Mean \pm SD. & $0.291 \pm 0.020$ & $0.280 \pm 0.022$ & $0.260 \pm 0.021$ & $X^{2}=5.173$ \\
Genotype & & & & 0.270 \\
GG & 8 & 8 & 5 & \\
GA & 4 & 17 & 1 & \\
AA & 0 & 1 & &
\end{tabular}

other potential insulin resistance confounding factors in some studies, recruitment procedures of the studied subjects, genetic heterogeneity, and differences in linkage disequilibrium between different populations as well as environmental backgrounds that might influence their phenotypes and may have an impact on the studied results.

In the current study, it was concluded that there was a statistically significant difference regarding HOMA-IR and QUICKI index among different Child classes in groups III and IV, with HOMA-IR tending to increase and QUICK index tending to decrease with the increasing severity of liver cirrhosis. In agreement with our results, Hideki Fujii et al. [37] concluded that HOMA-IR is an independent risk factor of advanced liver fibrosis in non-alcoholic and non-diabetic fatty liver disease. On the other hand, Dongiovanni et al. [38] had concluded that IRS-1 972Arg polymorphisms affecting insulin receptor activity predispose to liver damage and decrease hepatic insulin signaling in patients with NAFLD. This finding was in concordance with our conclusion of the lack of statistically significant difference regarding IRS-1 genotypes between different liver cirrhosis Child-Pugh classes in both liver patient groups (Tables 6 and 7). This disagreement can be attributed to different etiology of the liver cirrhosis between the current study, HCV infection, and Dongiovanni et al. study which was conducted on non-alcoholic liver disease patients.

\section{Conclusions}

From this study, it could be concluded that:

$\checkmark$ IRS-1 G972R (rs 1801278) polymorphism might be contributing risk factors for the development of type 2 $\mathrm{DM}$ as established by the high frequency of minor allele (A) in type 2 diabetic patients without chronic hepatitis C infection. $\checkmark$ The increased frequency of mutant allele (A) than wild allele (G) of IRS-1 G972R polymorphism in type 2 diabetic patients with $\mathrm{BMI}<25 \mathrm{~kg} / \mathrm{m}^{2}$ suggests the role of these SNPs as risk factors for type 2 diabetes mellitus even in subjects with normal body weight.

$\checkmark$ The significant increase of body mass index in type 2 diabetics without $\mathrm{HCV}$ infection and $\mathrm{HCV}$-infected patients with type 2 diabetes mellitus indicates its role as an independent risk factor for the development of type 2 diabetes mellitus.

$\checkmark$ The study of other related gene polymorphisms that might contribute to the development of type $2 \mathrm{DM}$ in chronic hepatitis $\mathrm{C}$ patients and additional studies on the association between IRS-1 G972R polymorphism and DM complications and its relation to the antidiabetic therapy response are recommended to be conducted on larger sample size; also, in the light of our study, it could be recommended that assessment of gene expression of IRS-1 in chronic hepatitis C-infected patients might be useful for early detection of type 2 diabetes in these patients.

Limitation of the study:

- Small size of subjects

- Lack of data about HCV genotype in the studied group

Acknowledgements

Not applicable.

Authors' contributions

SO analyzed and interpreted the patient data regarding the liver disease. EA performed the laboratory and molecular studies and was a major contributor in writing the manuscript. AW supervised the laboratory studies and subject selections. RB shared in research idea formulation and study design, and GM validated the data and managed and supervised the whole work. All authors read and approved the final manuscript.

Funding

This research is conducted by self-funding. 


\section{Availability of data and materials}

The datasets used and/or analyzed during the current study are available from the corresponding author on reasonable request.

\section{Ethics approval and consent to participate}

The study was conducted after approval of the Medical Research Institute, Alexandria University Ethical committee, no available reference number, and according to the Helsinki Declaration. The study was explained to all participating subjects, and written informed consents were taken from all of them.

\section{Consent for publication}

Not applicable.

\section{Competing interests}

The authors declare that they have no competing interests.

\section{Author details}

${ }^{1}$ Chemical Pathology Department, Medical Research Institute, Alexandria University, Alexandria, Egypt. ${ }^{2}$ Experimental and Clinical Internal Medicine, Medical Research Institute, Alexandria University, Alexandria, Egypt.

Received: 3 June 2020 Accepted: 24 November 2020

Published online: 06 January 2021

\section{References}

1. Doss W, Shiha G, Hassany M, Soliman R, Fouad R et al (2015) Sofobuvir plus ribavirin for the treatment of Egyptian patients with hepatitis $C$ genotype 4 . J Hepatol 15:306-302

2. Mohamed R, Saeed R, Oun AR, Abdel-Halim K, Abdel-Aal M et al (2015) Hepatitis $C$ virus vertical transmission in a sample of Egyptian pregnant women. J Am Sci 11:40-46

3. Negro F, Alaei M (2009) Hepatitis C virus and type 2 diabetes. World J Gastroenterol 15:1537-1547

4. Alvares da Silva MR, Wedemeyer H, Pinto HC, Souza CPM (2012) Hepatitis C and metabolic disorders: genetics, mechanism, and therapies (clinical and experimental). Int J Hepatol 2012:937202-937204

5. El Ray A, Asselah T, Moucari R, El Ghannam M, Taha AA et al (2013) Insulin resistance: a major factor associated with significant liver fibrosis in Egyptian patients with genotype 4 chronic hepatitis C. Eur J Gastroenterol Hepatol 25:421-427

6. Zakaria E, Fayad T, Rizk MN, Ghanem NS, Kamal M (2013) Association between insulin resistance, metabolic syndrome, and duration of hepatitis C in Egyptian patients. Egypt J Intern Med 25:213-217

7. Sesti G, Federici M, Hribal ML, Lauro D, Sbraccia P et al (2001) Defects of the insulin receptor substrate (IRS) system in human metabolic disorders. FASEB J 15:2099-2111

8. Rowland AF, Fazakerley DJ, James DE (2011) Mapping insulin/GLUT4 circuitry. Traffic 12:672-681

9. Menting JG, Whittaker J, Margetts MB, Whittaker L, Kong GKW, Smith BJ et al (2013) How insulin engages its primary binding site on the insulin receptor. Nature 493:241-245

10. Araki E, Sun XJ, Haag BL 3rd, Chuang LM, Zhang Y et al (1993) Human skeletal insulin receptor sustrate-1. Characterization of the CDNA, gene, and chromosomal localization. Diabetes 42:1041-1054

11. Alharbi KK, Khan IA, Abotalib Z, Al-Hakeem MM (2014) Insulin receptor substrate-1 (IRS-1) Gly927Arg: correlation with gestational diabetes mellitus in Saudi women. BioMed Res Int 2014:146495-146499

12. Arikoglu H, Hepdogru MA, Kaya DE, Asik A (2014) IRS1 gene polymorphisms Gly972Arg and Ala513Pro are not associated with insulin resistance and type 2 diabetes risk in non-obese Turkish population. Meta Gene 2:579-585

13. Banerjee S, Saito K, Goughoulte MA, Meyer K, Ray RB et al (2008) Hepatitis C virus core protein upregulates serine phosphorylation of insulin receptor substrate-1 and impairs the downstream Akt/Protein kinase B signaling pathway for insulin resistance. J Virol 82:2606-2612

14. Daud S, Javaid F (2012) Estimation of body mass index (BMI) in medical students. PJMHS 5:702-705

15. Wang C, Wang B, He H, Li X, Wei D, Zhang J et al (2012) Association between insulin receptor gene polymorphism and the metabolic syndrome in Han and Yi Chinese. Asia Pac J Clin Nutr 21:457-463
16. Verslype C, Rosmorduc O, Rougier P, Group EGW (2012) Hepatocellular carcinoma: ESMO-ESDO clinical practice guidelines for diagnosis, treatment and follow-up. Ann Oncol 23(Suppl 7):vii41-vii48

17. Burtis CA, Ashwood ER, Bruns DE (2012) Tietz textbook of clinical chemistry and molecular diagnostics, 5th edn. Elsevier Saunders Company, St Louis pp. 676-9 (albumin creatinine ratio), 718-22(glucose), 771-8 (lipid profile), 680-4(creatinine), 690 (uric acid), 143-6 (ALT, AST and GGT)

18. Guojun Z, Yanguo T, Ranxing Z, Yan Z, Tao K et al (2013) Analysis of current status of serum insulin determination by different chemiluminescence immunoassay systems. J Cap Med Univ 34:545-549

19. Matthews DR, Hosker JP, Rudenski AS, Naylor BA, Treacher DF, Turner RC (1985) Homeostasis model assessment: insulin resistance and beta-cell function from fasting plasma glucose and insulin concentrations in man. Diabetologia 28:412-419

20. Rabasa-Lhoret R, Bastard JP, Jan V (2003) Modified quantitative insulin sensitivity check index is better correlated to hyperinsulinemic glucose clamp than other fasting-based index of insulin sensitivity in different insulin-resistant states. J Clin Endocrinol Metab 88:4917-4923

21. Chakravarti A, Charhan MS, Dogra G, Banerjee S (2013) Hepatitis C virus core antigen assay: can we think beyond convention in resource limited settings? Braz J Infect Dis 17:369-374

22. Dufour R (2006) Hepatitis B surface antigen (HBs Ag) assays- are they good enough for their current uses? Clin Chem 52:1457-1459

23. Elmougy FA, Morgan MF, Elgayar DF, Mohey AM, Baz HN et al (2011) Allelic variants of insulin receptor substrate-1 gene in Egyptian women with polycystic ovary syndrome. Comp Clin Pathol 21:1689-1696

24. Shaker O, Abdel Hafez MA, Fayez S, Alsherif YM (2015) Phosphatidylinositol 3-kinase and insulin receptor substrate-1 gene polymorphism/ adipocytokines interaction in pathogenesis of insulin resistance among Egyptian patients: a pilot study. IJRSB 3(9):81-93

25. El-sisi AE, Hegazy SK, Metwally SS, Wafa AM, Dawood NA (2011) Effect of genetic polymorphisms on the development of secondary failure to sulfonylurea in Egyptian patients with type 2 diabetes. Adv Endocrinol Metab 2(4):155-164

26. Yousef AA, Behiry EG, Abd Allah WM, Hussien AM, Abdelmoneam AA, Imam MH et al (2018) IRS-1 genetic polymorphism (r.2963G>A) in type 2 diabetes mellitus patients associated with insulin resistance. Appl Clin Genet 11:99-106

27. Sir-Petermann T, Pérez-Bravo F, Angel B, Maliqueo M, Calvillan M, Palomino A (2001) G972R polymorphism of IRS-1 in women with polycystic ovary syndrome. Diabetologia 44(9):1200-1201

28. Sir-Petermann T, Angel B, Maliqueo M, Santos $\lrcorner$, Riesco MV, Toloza H et al (2004) Insulin secretion in women who have polycystic ovary syndrome and carry the Gly972Arg variant of insulin receptor substrate-1 in response to a high-glycemic or low-glycemic carbohydrate load. Nutrition 20(10):905-910

29. Villuendas G, Botella-Carretero Jl, Roldán B, Sancho J, Escobar-Morreale HF, San Millán JL (2005) Polymorphisms in the insulin receptor substrate-1 (IRS-1) gene and the insulin receptor substrate-2 (IRS-2) gene influence glucose homeostasis and body mass index in women with polycystic ovary syndrome and non-hyperandrogenic controls. Hum Reprod 20(11):3184-3191

30. Dravecká I, Lazúrová I, Habalova V (2010) The prevalence of Gly972Arg and C825T polymorphisms in Slovak women with polycystic ovary syndrome and their relation to the metabolic syndrome. Gynecol Endocrinol 26(5):356-602

31. McGettrick AJ, Feener EP, Kahn CR (2005) Irs-1 Human insulin receptor substrate-1 (IRS-1) polymorphism G972R causes IRS-1 to associate with the insulin receptor and inhibit receptor autophosphorylation. J Biol Chem 280(8):6441-6446

32. Burguete-Garcia Al, Cruz-Lopez M, Madrid-Marina V, Lopez-Ridaura R, Hernandez-Avila M et al (2010) Association of Gly972Arg polymorphism of IRS1 gene with type 2 diabetes mellitus in lean participants of a national health survey in Mexico: a candidate gene study. Metabolism 59:38-45

33. Huri HZ, Makmor-Bakry M, Hashim R, Mustafa N, Wan Ngah WZ (2012) Optimisation of glycaemic control during episodes of severe/acute hyperglycaemia in patients with type 2 diabetes mellitus. Int J Clin Pharm 34:863-870

34. Zeggini E, Parkinson J, Halford S, Owen KR, Frayling TM et al (2004) Association studies of insulin receptor substrate 1 gene (IRS1) variants in type 2 diabetes samples enriched for family history and early age of onset. Diabetes 53:3319-3322

35. Bodhini D, Phil M, Radha V (2011) Association study of IRS1 gene polymorphisms with type 2 diabetes in South Indians. Diabetes Technol Ther 13(7):767-772 
36. Alsalman HA, Kaabi YA (2015) Lack of association between the insulin receptor substrates-1 Gly972Arg polymorphism and type-2 diabetes mellitus among Saudis from Eastern Saudi Arabia. Saudi Med J 36(12):1420-1424

37. Fujii H, Imajo K, Yoneda M, Nakahara T, Hyogo H, Takahashi H et al (2019) HOMA-IR: An independent predictor of advanced liver fibrosis in nondiabetic non-alcoholic fatty liver disease. J Gastroenterol Hepatol 34(8): 1390-1395

38. Dongiovanni P, Valenti L, Rametta R, Daly AK, Nobili V, Mozzi E et al (2010) Genetic variants regulating insulin receptor signalling are associated with the severity of liver damage in patients with non-alcoholic fatty liver disease. Gut 59(2):267-273

\section{Publisher's Note}

Springer Nature remains neutral with regard to jurisdictional claims in published maps and institutional affiliations.

\section{Submit your manuscript to a SpringerOpen ${ }^{\circ}$ journal and benefit from:}

- Convenient online submission

- Rigorous peer review

- Open access: articles freely available online

High visibility within the field

- Retaining the copyright to your article

Submit your next manuscript at $\boldsymbol{\nabla}$ springeropen.com 